\title{
Examination of the Responses of Different Genotypes of Citrus to Huanglongbing (Citrus Greening) Under Different Conditions
}

\author{
Svetlana Y. Folimonova, Cecile J. Robertson, Stephen M. Garnsey, Siddarame Gowda, and William O. Dawson
}

Citrus Research and Education Center, University of Florida, 700 Experiment Station Road, Lake Alfred 33850.

Accepted for publication 13 July 2009.

\begin{abstract}
Folimonova, S. Y., Robertson, C. J., Garnsey, S. M., Gowda, S., and Dawson, W. O. 2009. Examination of the responses of different genotypes of citrus to Huanglongbing (citrus greening) under different conditions. Phytopathology 99:1346-1354.

Citrus Huanglongbing (HLB) is one of the most devastating diseases of citrus worldwide. The causal agent of HLB in Florida is thought to be 'Candidatus Liberibacter asiaticus'. In this work, we examined the responses of 30 different genotypes of citrus to Florida isolates of ' $\mathrm{Ca}$. $\mathrm{L}$. asiaticus' under controlled conditions in the greenhouse or growth room. Although ' $\mathrm{Ca}$. L. asiaticus' was able to multiply in all of the plants, a wide range of responses was observed among different hosts. Based on the symptoms developed and the ability of plants to continue growth, the different genotypes were grouped into four categories: sensitive, which exhibited severe chlorosis on leaves, greatly reduced growth, and eventual death; moderately tolerant, which exhibited some scattered distinct symptoms but little or no growth reduction and no plant death; tolerant, which exhibited very minimal symptoms; and genotypes, which exhibited

variable reactions. Interestingly, although ' $\mathrm{C}$. L. asiaticus' was unevenly distributed within each particular plant, comparison of titers of the bacterium in different citrus genotypes revealed that most accumulated similar levels of ' $\mathrm{Ca}$. L. asiaticus', demonstrating that there is no strict correlation between bacterial titer and severity of disease. Incubation of infected plants in the growth room with continuous light greatly affected symptoms production by reducing the time before distinctive symptoms developed and significantly increasing severity of chlorosis of leaves of all citrus genotypes. These results provide additional evidence of the correlation between disruption of phloem translocation of carbohydrates during HLB infection and the appearance of chlorotic symptoms in leaves of infected trees. We also examined interaction between ' $\mathrm{Ca}$. L. asiaticus' and Citrus tristeza virus, which usually occurs in trees that become infected with HLB, and found no synergistic effect of the two pathogens. We trust that observations reported here will provide reagents for further examination of the ' $\mathrm{Ca}$. L. asiaticus'-citrus interaction to advance the understanding of how ' $\mathrm{Ca}$. L. asiaticus' causes disease and to develop methods or trees to overcome the disease.
\end{abstract}

Citrus greening (Huanglongbing [HLB]) is one of the most devastating diseases of citrus worldwide $(2,4,5)$ and now is threatening the survival of the citrus industry in Florida (9). Three species of 'Candidatus Liberibacter'- 'Candidatus Liberibacter asiaticus', 'Ca. L. africanus', and ' $C a$. L. americanus' $(2,15)-$ plus phytoplasma $(3,22)$ have been found associated with citrus greening in citrus-growing areas in the world. The causal agent of HLB in Florida is thought to be primarily ' $\mathrm{Ca}$. L. asiaticus'. However, based on the fact that Koch's postulates have not yet been fulfilled, the presence of other organisms and their association with the disease cannot be ruled out.

HLB was first discovered in Florida in 2005 in dooryard trees in the Miami area, 7 years after introduction and establishment of the psyllid vector (Diaphorina citri). Soon afterward, it was found in a few commercial citrus groves in the southernmost regions. Since then, it has spread rapidly to all citrus-growing regions in Florida. There are several reasons why the disease is spreading so rapidly. The bacterium multiplies in the psyllid vector, which was recently introduced into Florida (1998), and biological enemies have not yet developed sufficiently to restrict populations. The cultural methods that provide vigorous growth of citrus and high yields produce many flushes that enhance the psyllid populations. Overall, the Florida citrus environment presents almost insurmountable challenges to controlling HLB. The insect vector is spreading toward all citrus-growing areas in the United States.

Corresponding author: W. O. Dawson; E-mail address: wodtmv@crec.ifas.ufl.edu

doi:10.1094/PHYTO-99-12-1346

(c) 2009 The American Phytopathological Society
' $C a$. L. asiaticus' belongs to the group of $\alpha$-proteobacteria and resides within the phloem of citrus. ' $\mathrm{Ca}$. L. asiaticus' infection causes a decline of infected trees, loss of fruit due to early abortion, and adverse effect on fruit quality such as small size, lopsided shape, and poor flavor. Leaf symptoms vary from complete yellowing, asymmetric blotchy-mottling, or other chlorotic patterns that sometimes resemble mineral deficiency to severe vein corking $(2,4,18)$. Massive starch accumulation and disruption of chloroplasts were found to be associated with vein phloem collapse in ' $\mathrm{Ca}$. L. asiaticus'-infected leaves and could account for the appearance of symptoms described above (18).

A characteristic of ' $\mathrm{Ca}$. L. asiaticus' is that different degrees of disease and symptoms are induced in different types of plants. In fact, the citrus relative and common landscaping plant, Murraya paniculata (L.) Jack (orange jasmine), which has been suggested as a participant of the spread of citrus greening, often has minimal symptoms (16). On the other hand, there is a range of other citrus genotypes that are more susceptible to the disease, though they demonstrate significant differences in host reactivity to HLB, as described in earlier observations of infected field trees $(6,8,11)$.

Furthermore, different isolates of ' $\mathrm{Ca}$. L. asiaticus' can cause different amounts of disease in citrus cultivars. For example, inoculation of different citrus hosts with ' $\mathrm{Ca}$. L. asiaticus' conducted in Taiwan resulted in significant differences between several isolates of ' $\mathrm{Ca}$. L. asiaticus' in their ability to induce disease in cultivars like Eureka lemon (Citrus limon (L.) Burm. F.) and pummelo ( $C$. maxima (Burm.) Merr.) ranging from the absence of bacteria and no symptoms to high concentrations of ' $C a$. L. asiaticus' and the development of severe symptoms (23). At the same time, most isolates were similar in the degree of disease 
induced in other citrus cultivars such as mandarin (C. reticulata Blanco) and sweet orange (C. sinensis (L.) Osbeck).

Most information on different citrus host reactions to HLB have been accumulated from observations made under different conditions, often from field trees at different geographical locations, at different times, and when other graft-transmissible pathogens may have been present. In this work, we conducted examinations of the responses to Florida isolates of ' $\mathrm{Ca}$. L. asiaticus' by a wide range of different genotypes of citrus under controlled conditions, side by side in the greenhouse or growth room. The objectives in this study were to develop an understanding at the whole-plant level of how different citrus genotypes respond to ' $\mathrm{Ca}$. L. asiaticus' infection, whether there are resistant or tolerant cultivars, whether there is a correlation between severity of disease and the level of bacterial concentration, how ' $\mathrm{Ca}$. L. asiaticus' is distributed within infected plants, what are the effects of environmental conditions, specifically light, on symptom development, and whether there is an interaction between ' $\mathrm{Ca}$. L. asiaticus' and Citrus tristeza virus (CTV), which is ubiquitous in Florida citrus.

\section{MATERIALS AND METHODS}

Plant materials, inoculations, and plant growing conditions. Citrus germplasm used in these studies was obtained from DPI (FDACS Division of Plant Industry) or the United States Department of Agriculture (USDA) CRC (USDA Agricultural Research Service National Clonal Germplasm Repository for Citrus and Dates). Thirty citrus cultivars or relatives were used in this work and are listed in Table 1. Plants were propagated either as seedlings or as scions on either Volkamer lemon or Carrizo citrange rootstocks, and 6- to 8-month-old seedlings were used for inoculation with ' $\mathrm{Ca}$. L. asiaticus'-infected budwood. All plants were graft inoculated with two to three pieces of budwood from polymerase chain reaction (PCR)-positive HLB source trees. Usually, six trees per treatment along with two noninoculated trees as controls were used in the experiments. The inoculum (infected buds) was left permanently in the inoculated trees except in the indicated experiment below, in which we removed inoculum at 4, $6,8,10$, or 12 weeks after grafting to Cleopatra mandarin seedlings to examine a time period necessary for initiation of infection upon grafting of the infectious tissue. Inoculated plants were kept in a USDA Animal and Plant Health Inspection Service-approved secure greenhouse with a temperature of 26 to $32^{\circ} \mathrm{C}$ or growth room at $28^{\circ} \mathrm{C}$. Photosynthetically active radiation (PAR) was measured using a LI-185 Quantum Radiometer/Photometer (Lambda Instruments Inc., Lincoln, NE). PAR measured above plants in the greenhouse with natural photoperiods was 300 to $570 \mu \mathrm{Em}^{-2} \mathrm{~s}^{-1}$ during the daytime. The PAR value measured in the growth room was $300 \mu \mathrm{Em}^{-2} \mathrm{~s}^{-1}$. The growth room had a 24-h photoperiod.

Characterization of HLB field inoculum sources. HLB inoculum was obtained from three field sources for these experiments. These were coded as field collection (FC)4, FC5, and FC6. FC4 was collected from symptomatic field trees located in Hendry County near the forefront of the commercial invasion, FC5 from Miami-Dade County near the original find of the disease in Florida, and FC6 from a grove in Highlands County near the center of the citrus-producing area and near the upper reaches of the invasion at the time. All inoculum sources were verified to have HLB via real-time quantitative PCR (qPCR) assays with ' $\mathrm{Ca}$. L. asiaticus'-specific primers and for the presence of CTV using a double-antibody sandwich indirect enzymelinked immunosorbent assay (ELISA) according to procedures described below.

As soon as we were approved to work with the 'Select Agent' in our greenhouse (31 January 2007), young trees of Carrizo citrange, Madam Vinous sweet orange, Sun Chu Sha mandarin, Duncan grapefruit, C. macrophylla, and Eureka lemon were graft inoculated using FC4, FC5, or FC6 inoculum and maintained in the greenhouse. At 3 and 6 months after grafting, plants were observed for symptoms and sampled for qPCR detection of ' $\mathrm{Ca}$. L. asiaticus'.

TABLE 1. Response of different Citrus genotypes to grafting with buds from 'Candidatus Liberibacter asiaticus'-infected trees

\begin{tabular}{|c|c|c|}
\hline Citrus or relative & 'Ca. L. asiaticus'a & Symptom description \\
\hline Citrus halimii B. C. Stone & ++ & Sensitive_chlorosis, vein corking, death \\
\hline Nules clementine ( $C$. reticulata Blanco) & ++ & Sensitive-chlorosis to tip leaves, reduced growth, death \\
\hline Minneola tangelo ( $C . \times$ tangelo J. Ingram \& H. E. Moore $)$ & ++ & Sensitive_chlorosis to tip leaves, reduced growth \\
\hline Valencia sweet orange (C. sinensis $(\mathrm{L}$.$) Osbeck)$ & +++ & Sensitive-chlorosis including tip, reduced growth, death \\
\hline Madam Vinous sweet orange (C. sinensis (L.) Osbeck) & +++ & Sensitive-chlorosis including tip, reduced growth, death \\
\hline Duncan grapefruit (C. paradisi MacFadyen) & ++ & Sensitive - chlorosis including tip, reduced growth, death \\
\hline Ruby red grapefruit (C. paradisi MacFadyen) & ++ & Sensitive—chlorosis to tip leaves, reduced growth \\
\hline Siamese Sweet pummelo (C. maxima (Burm.) Merr.) & ++ & Variable-mild symptoms in $\mathrm{GH}$, strong under $24 \mathrm{~h}$ of light \\
\hline Ling Ping Yau pummelo (C. maxima (Burm.) Merr.) & ++ & Variable-mild symptoms in $\mathrm{GH}$, strong under $24 \mathrm{~h}$ of light \\
\hline Hirado Buntan Pink pummelo (C. maxima (Burm.) Merr.) & ++ & Variable_-strong symptoms in young and old leaves \\
\hline C. amblycarpa (Hassk.) Ochse & +++ & Variable_-chlorosis and some reduction of growth \\
\hline Cleopatra mandarin (C. reticulata Blanco) & +++ & Variable - chlorotic leaves, some reduction of growth \\
\hline C. indica Tanaka & ++ & Variable — early chlorosis, severe under $24 \mathrm{~h}$ of light \\
\hline Meiwa kumquat (Fortunella crassifolia Swingle 'Meiwa') & ++ & Variable_chlorotic leaves, plant growth reduced \\
\hline Sun Chu Sha mandarin (C. reticulata Blanco) & +++ & Moderately tolerant-scattered chlorotic groups of leaves \\
\hline Sour orange (C. aurantium L.) & +++ & Moderately tolerant—chlorosis under high light only \\
\hline Volkamer lemon (C. limonia Osbeck 'Volkameriana') & +++ & Moderately tolerant-scattered chlorotic groups of leaves \\
\hline C. macrophylla Wester & +++ & Moderately tolerant—scattered chlorotic groups of leaves \\
\hline Swingle citrumelo (X Citroncirus webberi J. Ingram \& H. E. Moore) & +++ & Moderately tolerant—some yellowing of older leaves \\
\hline Citron (Citrus medica L.) & ++ & Moderately tolerant—strong symptoms on older leaves \\
\hline Palestine Sweet lime (C. aurantifolia (Christm.) Swingle) & +++ & Moderately tolerant—-some chlorosis on older leaves \\
\hline Mexican lime(C. aurantifolia (Christm.) Swingle) & +++ & Moderately tolerant—scattered chlorotic groups of leaves \\
\hline Calamondin (X Citrofortunella microcarpa (Bunge) Wijnands) & +++ & Moderately tolerant—mild symptoms on older leaves \\
\hline Citrus micrantha Wester & +++ & Moderately tolerant-mild symptoms on older leaves \\
\hline Eureka lemon (C. limonia Osbeck) & ++ & Tolerant-no symptoms, chlorosis under $24 \mathrm{~h}$ of light only \\
\hline Persian lime (C. aurantifolia (Christm.) Swingle) & +++ & Tolerant-little or no symptoms \\
\hline Carrizo citrange (X Citroncirus webberi J. Ingram \& H. E. Moore) & + & Tolerant-little or no chlorosis \\
\hline Severinia buxifolia (Poiret) Ten. & + & Tolerant-no distinct symptoms \\
\hline Poncirus trifoliata (L.) Raf. & $+/-$ & Inconsistent \\
\hline Citrus latipes (Swingle) & $+/-$ & Inconsistent \\
\hline
\end{tabular}

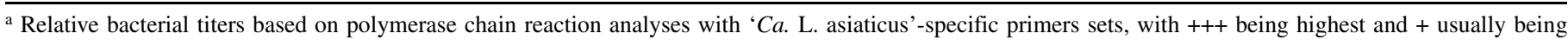
low but definitely positive. $\mathrm{GH}=$ greenhouse. 
Host responses to ' $\boldsymbol{C a}$. L. asiaticus'. Thirty different citrus cultivars or relatives (Table 1) were graft inoculated with the CTV-free FC6 source of HLB inoculum. Visual observations of symptoms along with PCR assays with ' $\mathrm{Ca}$. L. asiaticus'-specific oligonucleotide primers of the extracted DNA samples were performed at different time points, and analyses continued until 1 year after inoculation.

Distribution of ' $\mathrm{Ca}$. L. asiaticus' within infected plants. Samples of leaf tissue were collected from symptomatic and nonsymptomatic leaves of ' $C a$. L. asiaticus'-infected plants and assayed for ' $C a$. L. asiaticus' using qPCR assays as described below. Symptomatic and nonsymptomatic tissues from infected C. macrophylla plants were also further used for graft inoculation of small sweet orange seedlings to examine efficiency of HLB graft transmission. Eighteen seedlings were used for each type of tissue. Establishment of infection was confirmed by PCR analysis conducted at 3 and 4 months after inoculation.

Effect of light and temperature on HLB symptoms. To examine HLB symptom development under different light conditions, we inoculated plants for incubation in a growth room with a 24-h photoperiod at the same time as we inoculated the 30 genotypes of citrus with ' $C a$. L. asiaticus'-infected buds for the greenhouse experiment described above. Conditions of growing plants in the greenhouse and growth room are indicated above. Because of space limitation, we examined 19 of the 30 genotypes. Observation of symptoms and $\mathrm{qPCR}$ tests were conducted as described earlier. At 7 months after the beginning of the experiment, we reversed conditions by switching infected symptomatic trees from the greenhouse to the continuous-light growth room and also those that were incubated in the growth room to the greenhouse to see how changing conditions affected existing symptoms and those that developed in subsequent growth. To examine temperature effect on HLB symptoms, we inoculated young trees of Sun Chu Sha mandarin and incubated them in reach-in growth chambers (Conviron Controlled Environments Limited, Winnipeg, Canada) at $20^{\circ} \mathrm{C}, 27^{\circ} \mathrm{C}$, or $32^{\circ} \mathrm{C}$. Plants were further assayed for symptoms and ' $\mathrm{Ca}$. L. asiaticus' titers as described above.

Examination of ' $C a$. L. asiaticus'-CTV interaction. $C$. macrophylla, Valencia sweet orange, and Volkamer lemon were graft inoculated with FC6 together with one of the following CTV strains: T36, T30, T68, T3, or VT. Plants were maintained in a growth room with $24 \mathrm{~h}$ of light along with proper controls that included inoculations with only one of the pathogens. Similar to the experiment discussed above, symptoms were observed and recorded, and assays for the multiplication of the virus and the bacterium were performed at 4 and 7 months after inoculation.

PCR assays. Samples of leaf tissue midrib (250 mg) were extracted in $2.5 \mathrm{ml}$ of extraction buffer (100 mM Tris-HCL, $\mathrm{pH}$ 8.0; $50 \mathrm{mM}$ EDTA; $500 \mathrm{mM} \mathrm{NaCl}$; and $10 \mathrm{mM}$ dithiothreitol). A portion of the extract $(1,300 \mu \mathrm{l})$ was transferred to a $1.5-\mathrm{ml}$ Eppendorf tube, and $90 \mu \mathrm{l}$ of $20 \%$ sodium dodecyl sulfate was added and incubated at $65^{\circ} \mathrm{C}$ for $30 \mathrm{~min}$. Following incubation, $500 \mu \mathrm{l}$ of $5 \mathrm{M}$ potassium acetate was added, mixed thoroughly, and incubated on ice for $20 \mathrm{~min}$. The mixture was centrifuged at $13,000 \mathrm{rpm}$ for $10 \mathrm{~min}, 400 \mu \mathrm{l}$ of supernatant was recovered, and DNA was precipitated by adding an equal volume of isopropanol and held at $-20^{\circ} \mathrm{C}$ overnight. The DNA was pelleted, washed, and resuspended in $100 \mu \mathrm{l}$ of water for PCR analysis. Conventional $\mathrm{PCR}$ and $\mathrm{qPCR}$ tests were performed as described previously (21). qPCR reactions were carried out using primer-probe sets HLBaspr plus a plant cytochrome oxidase (COX)-based primerprobe set (COXfpr) as indicated by $\mathrm{Li}$ et al. (12). All reactions were done in triplicate with positive, healthy, and water controls, and the mean value of the threshold cycle $(\mathrm{Ct})$ was analyzed. $\mathrm{Ct}$ values then were entered into the grand universal equation for citrus plants $(Y=13.82-0.2866 X)$ to calculate the number of
'Ca. L. asiaticus' cells per gram of tissue sampled as described previously (13).

Serological assays. ELISA was performed as described previously using antibody specific to CTV virions (7) to confirm presence of the virus. Purified immunoglobulin $\mathrm{G}$ from rabbit polyclonal antiserum CTV-908 $(1 \mu \mathrm{g} / \mathrm{ml})$ was used as coating antibody. ECTV 172, a broadly reactive CTV monoclonal antibody, was used as a detecting antibody.

\section{RESULTS}

Efficiencies of graft transmission of ' $\mathrm{Ca}$. L. asiaticus' to different citrus hosts. In all experiments, we were able to graft transmit the pathogen with efficiencies averaging $\approx 70$ to $90 \%$ for all tested citrus cultivars using inoculum from infected trees maintained in the greenhouse. We have seen no obvious differences in the efficiencies of ' $C a$. L. asiaticus' transmission to different citrus genotypes. In all of the experiments described above, the inoculum (infected buds) was left permanently in the inoculated trees. To examine a time period necessary for initiation of infection upon grafting of the infected tissue, we removed inoculum at different time points after grafting to Cleopatra mandarin seedlings. Even when inoculum was removed after 4 weeks, three of four plants became infected. Longer incubation periods yielded infection in four of four (6 weeks), two of three ( 8 weeks), three of four (10 weeks), and four of four (12 weeks) plants compared with three of five plants with nonremoved inoculum that developed infection. These results suggest that the HLB agent moves into receptor host rapidly after phloem connections are established with the donor tissue.

Characterization of HLB field inoculum sources. Initial tests of HLB inoculum sources collected at three different locations verified the presence of ' $\mathrm{Ca}$. L. asiaticus' in all of them. FC6 was confirmed by ELISA to be negative for presence of CTV, whereas FC4 and FC5 were both CTV positive. All of the six citrus cultivars that were graft inoculated with the HLB sources became infected and tested HLB positive, with no obvious differences noted in host responses to the different inoculum sources (data not shown). Also, there was no evidence of an effect of the CTV populations in FC4 and FC5 on the production of HLB symptoms. At the same time, there was substantial variation among the citrus cultivars in their reactions to infection, indicating the need of a more detailed examination of the host responses to ' $\mathrm{Ca}$. $\mathrm{L}$. asiaticus' in an expanded range of citrus genotypes.

Host responses to ' $\boldsymbol{C a}$. L. asiaticus'. Examination of the responses of 30 different genotypes of citrus to inoculation with the CTV-free ' $\mathrm{Ca}$. L. asiaticus' isolate demonstrated that, although ' $C a$. L. asiaticus' was able to multiply in most of the plants, a wide range of reactions was observed among the different plants (Table 1). Sweet orange and grapefruit were extremely sensitive, usually responding to infection with severe yellowing of young leaves, reduced growth, and eventual death, whereas Mexican lime, Sun Chu Sha mandarin, and Eureka lemon tolerated the infection much better (Fig. 1). The effect of HLB on the plants was differentiated most dramatically by whether the tree or the affected shoot continued growth. Although some trees developed distinctive symptoms on leaves-for example, the Sun Chu Sha mandarin (Fig. 1) - newer leaves developed reduced symptoms and growth was inhibited only marginally, in contrast to sweet orange and grapefruit, in which there was almost no new growth after acute chlorosis of a shoot (Fig. 1). Based on severity of symptoms and the ability of plants to continue growth, the different genotypes were grouped into four categories (Table 1): sensitive, moderately tolerant, tolerant, and variable. The most sensitive genotypes were $C$. halimii, Nules clementine mandarin, and Minneola tangelo, which usually were the first plants to die. Initial symptoms - chlorosis of the young leaves and vein corking on older ones-became visible early, $\approx 2$ months after inoculation 
of plants. With time, the leaf symptoms became more intense, accompanied by no new shoot growth. Several months later ( $\approx 6$ months after inoculation), most of those plants were dead. Sweet oranges and grapefruit were almost as sensitive, with symptoms developing slightly later and plants surviving slightly longer.

Plants of pummelos, $C$. amblycarpa, Cleopatra mandarin, $C$. indica, and Meiwa kumquat showed variable responses. Some shoots developed pronounced symptoms and cessation of growth like plants in the sensitive group, while other shoots continued to grow with minor symptoms like shoots of plants in the tolerant group. Plants in this group rarely died due to HLB.
Sun Chu Sha mandarin, sour orange, Volkamer lemon, $C$. macrophylla, Swingle citrumelo, citron, Palestine Sweet lime, Mexican lime, calamondin, and $C$. micrantha developed distinctive chlorotic symptoms but continued growth and were classified as "moderately tolerant". Usually, symptoms developed 3 to 6 months after graft inoculation on the newest flush of leaves but subsequent flushes had fewer symptoms or were symptomless (Fig. 1). Infected plants continued to survive and grow in the greenhouse.

Four citrus genotypes-Eureka lemon, Persian lime, Carrizo citrange, and Severinia buxifolia-were highly tolerant to HLB. Little or no visual symptoms developed under greenhouse condi-
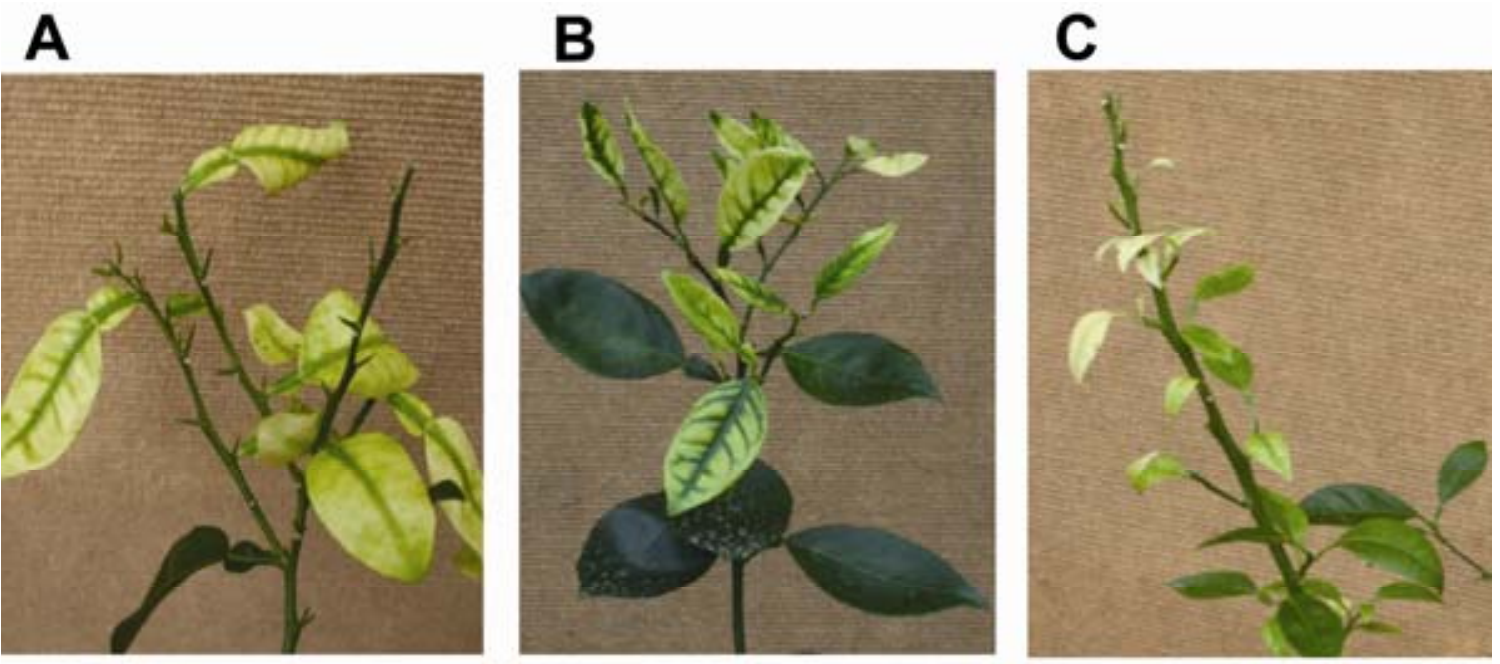

\section{D}

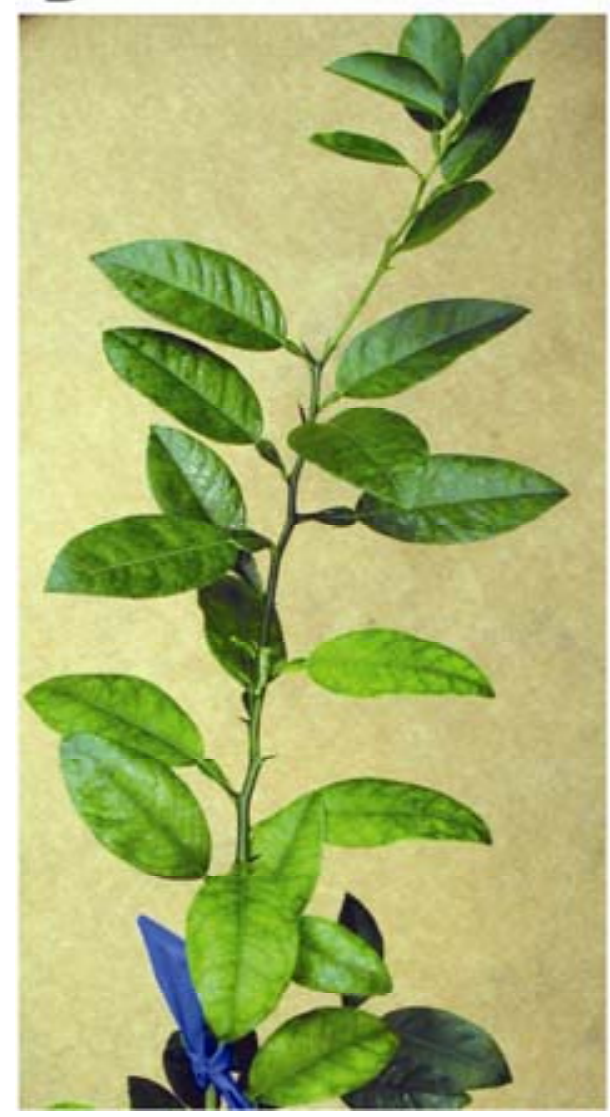

E
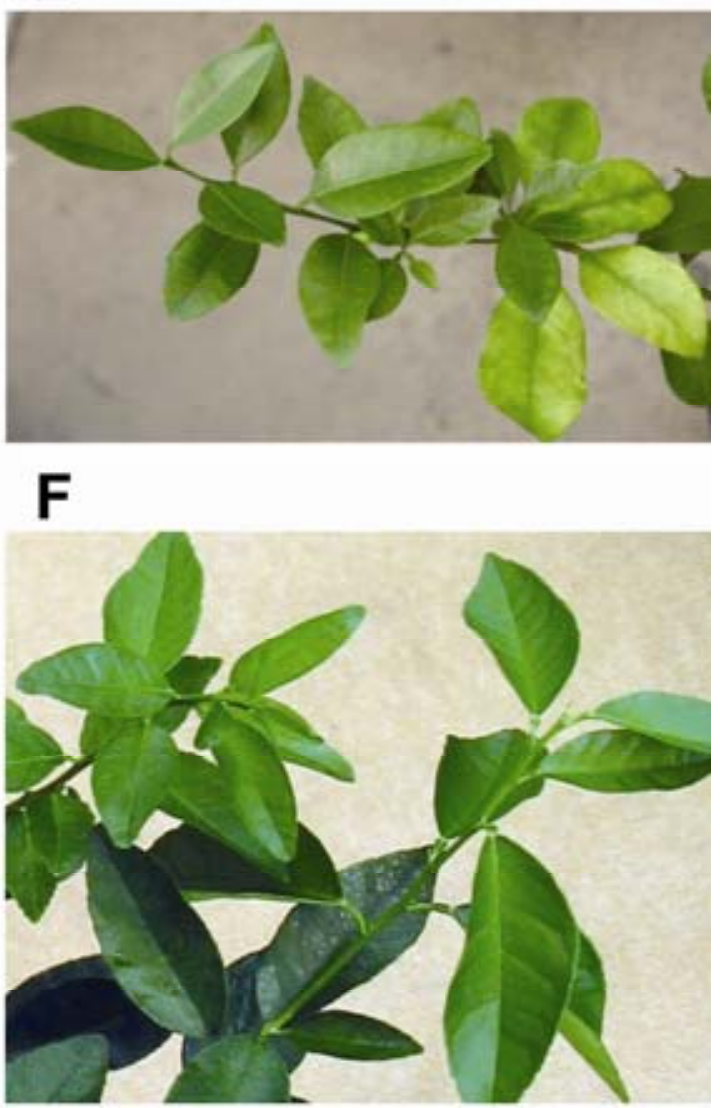

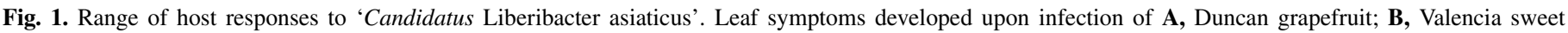
orange; C, Madam Vinous sweet orange; D, Mexican lime; E, Sun Chu Sha mandarin; and F, Eureka lemon at 6 months after inoculation. 
tions, and plants continued to grow vigorously, similar to noninoculated control trees.

Interestingly, all citrus genotypes tested positive for the presence of ' $\mathrm{Ca}$. L. asiaticus', with titers of the bacterium being similar for most cultivars (Table 1). Based on the fact that qPCR measurements of ' $\mathrm{Ca}$. L. asiaticus' titers vary considerably due to the uneven distribution of the bacterium within plants, which is discussed below, we conceptualized typical titers for each particular citrus genotype based on the range of results obtained over the year of analyses by assigning ratings to designate relative titers, with "three pluses" being highest and "one plus" usually being low but definitely positive (Table 1). Although Carrizo citrange and $S$. buxifolia exhibited reduced titers of ' $C a$. L. asiaticus',
Persian lime and Eureka lemon had relatively high titers of ' $\mathrm{Ca}$. L. asiaticus', which were comparable with titers of the bacterium found in more sensitive citrus hosts (Table 1), indicating that there was no clear correlation between severity of disease and level of bacterial concentration. Subinoculations of new sweet orange trees from Carrizo citrange and S. buxifolia, which showed lower titers of ' $\mathrm{Ca}$. L. asiaticus', resulted in development of typical HLB symptoms and high titers of the bacterium in sweet orange (data not shown).

Tests were also made on seedlings of Poncirus trifoliata and $C$. latipes but the results are not shown in Table 1 because of lack of consistency. In our first experiment, Poncirus seedlings appeared to be resistant to ' $C a$. L. asiaticus' and we could not confirm
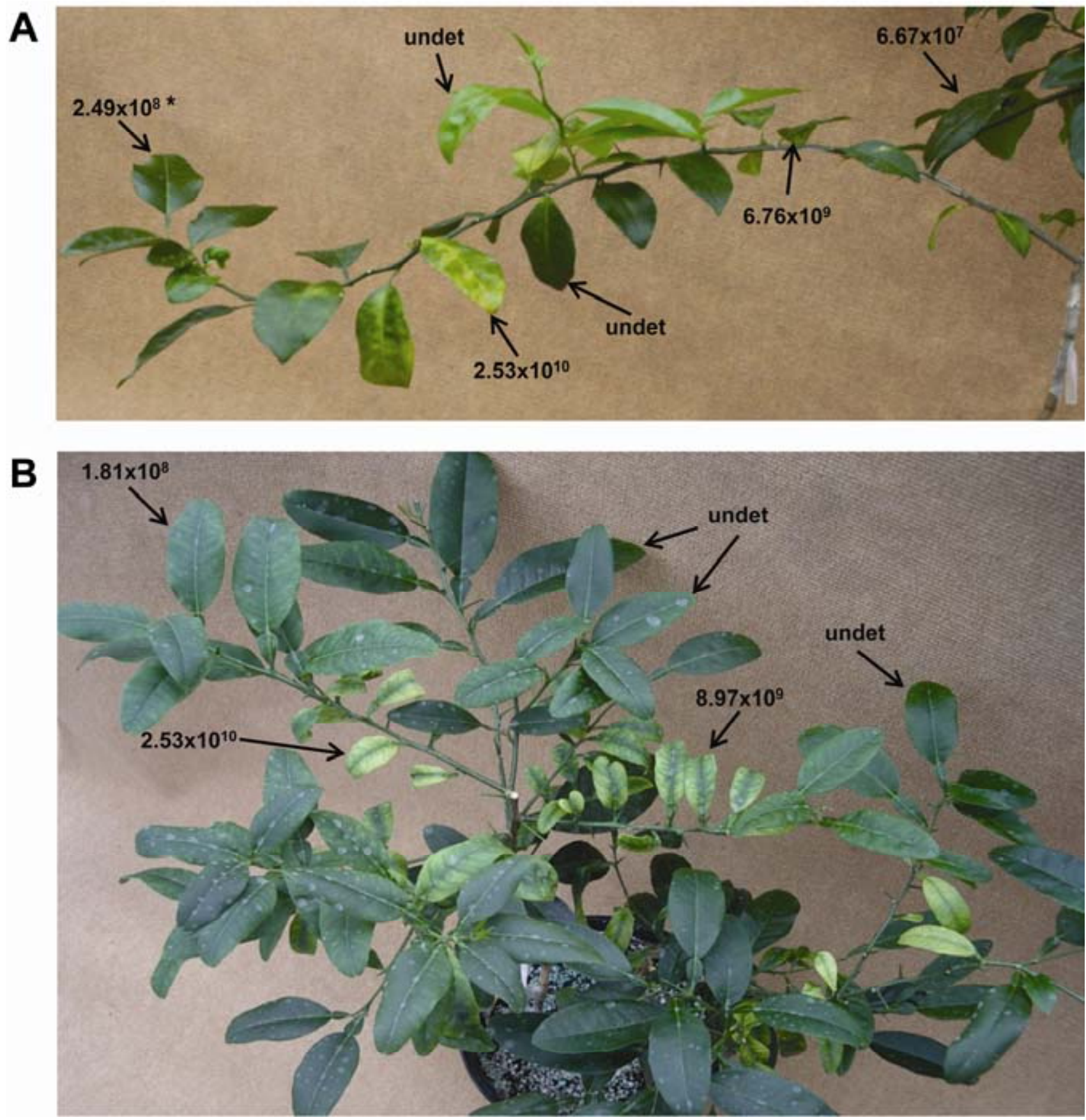

Fig. 2. Distribution of 'Candidatus Liberibacter asiaticus' in ' $C a$. L. asiaticus'-infected plants of A, Sun Chu Sha mandarin and B, Citrus macrophylla. Asterisk (*): number of ' $C a$. Liberibacter asiaticus' cells present per gram of fresh tissue; Undet: undetected. To calculate the number of cells per gram of tissue sampled, quantitative polymerase chain reaction (qPCR) was performed using primer-probe set HLBaspr (12) and $1 \mu \mathrm{l}$ of a 100- $\mu$ l DNA extract from $250 \mathrm{mg}$ of leaf midribs of ' $C a$. L. asiaticus'-infected plants. The qPCR data (threshold cycle values) then were entered into the grand universal equation for citrus plants: $Y=13.82-$ $0.2866 X(13)$. Undet indicates undetected. 
infection by PCR assays. In a subsequent test, inoculated seedlings did show symptoms and infection could be confirmed by qPCR. In our first experiment with $C$. latipes, inoculated seedlings developed symptoms but ' $\mathrm{Ca}$. L. asiaticus' was not detected in extracts from these plants by qPCR. In a repeat experiment, inoculated $C$. latipes plants developed symptoms again but these differed somewhat from those in the first test and extracts from these plants tested positively for ' $C a$. L. asiaticus' by qPCR. Further testing is in progress with both hosts to clarify the reasons for the discrepancies noted.

Distribution of ' $\mathrm{Ca}$. L. asiaticus' within infected plants. Examination of ' $\mathrm{Ca}$. L. asiaticus' distribution in infected plants demonstrated that, in all of the hosts, there was an uneven distribution of ' $\mathrm{Ca}$. L. asiaticus'. Distribution of the bacterium in the infected plants of Sun Chu Sha mandarin and C. macrophylla (moderately tolerant) is presented in Figure 2 as numbers of ' $C a$. L. asiaticus' cells per gram of plant tissue. Generally, higher titers of ' $\mathrm{Ca}$. L. asiaticus' were associated with symptomatic areas $\left(10^{9}-10^{10}\right.$ cells/g of tissue). qPCR assays of the nonsymptomatic tissue located next to the symptomatic area for different hosts showed that this tissue sometimes did and sometimes did not contain detectable amounts of the bacterium (Fig. 2). ' $C a$. L. asiaticus' distribution was further analyzed via examination of efficiency of graft transmission of HLB using donor tissue from symptomatic or nonsymptomatic areas of infected $C$. macrophylla. Upon inoculation of 18 sweet orange seedlings with symptomatic tissue; 3 plants did not have survived grafts; however, 11 of the remaining 15 plants became infected. At the same time, the grafts of all 18 seedlings inoculated with nonsymptomatic tissue survived and 10 plants developed infection, demonstrating comparable infection levels.

Effect of light and temperature on HLB symptoms. Plants incubated under continuous light showed much greater chlorosis (Fig. 3) and significantly shorter incubation periods for symptom expression. Graft-inoculated Madam Vinous sweet orange plants developed only mild chlorotic symptoms on young leaves after 3 months in the greenhouse, whereas plants under continuous light showed very strong yellowing of the majority of leaves in the same period. There was some impact of this light condition on uninoculated plants, which grew less vigorously and had paler leaves than the plants kept in the greenhouse. However, the effect of continuous light on the noninoculated plants was negligible compared with that of the infected plants. Furthermore, the extended light period caused chlorosis in some of the genotypes that
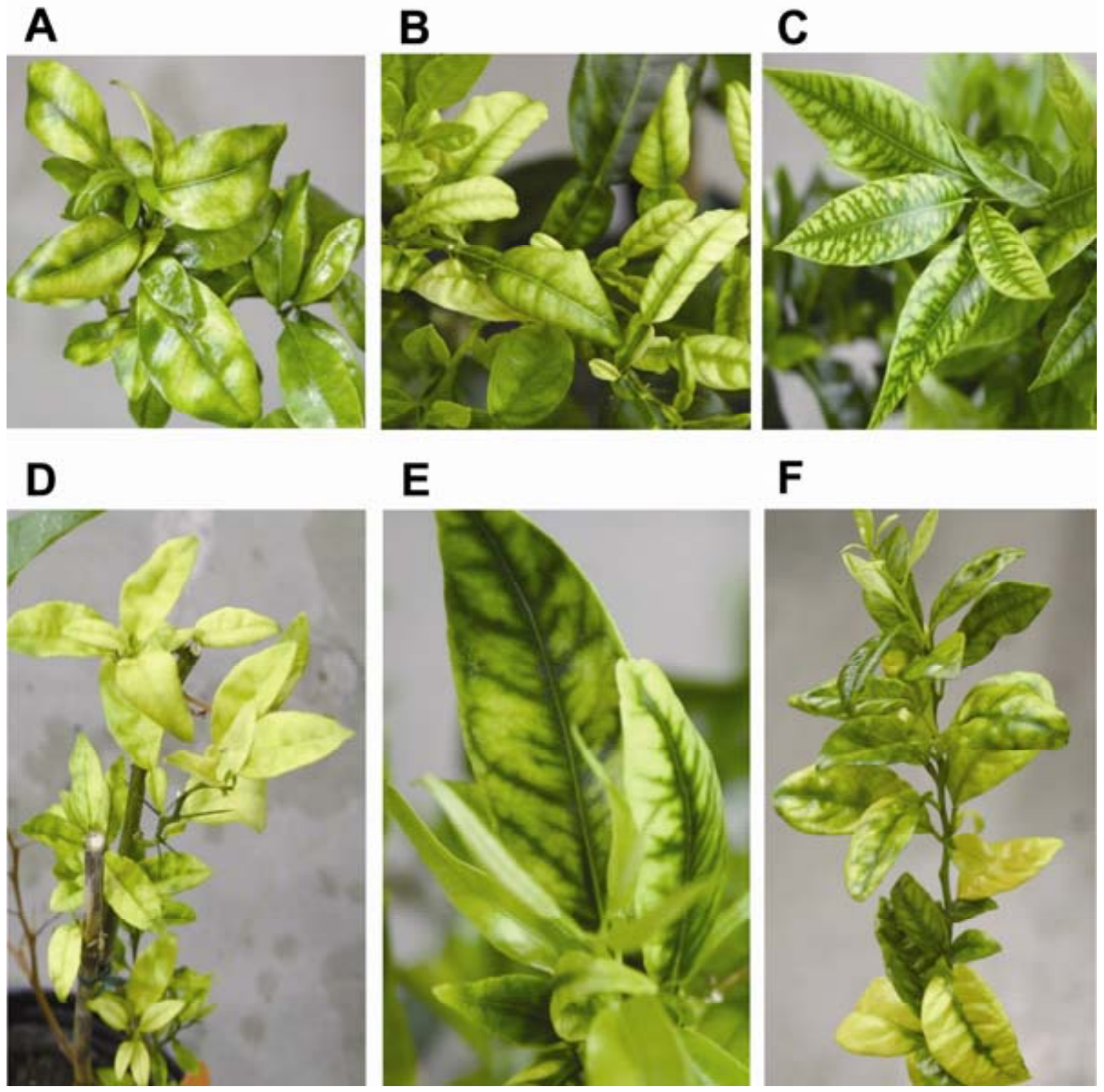

Fig. 3. Effect of continuous light on symptom production in different citrus genotypes. A, Sun Chu Sha mandarin; B, Siamese Sweet pummelo; C, Eureka lemon; D, Madam Vinous sweet orange; E, Nules clementine; and F, Cleopatra mandarin. Plants graft inoculated with 'Candidatus Liberibacter asiaticus'-infected tissue were kept in the growth room with a 24-h photoperiod. Pictures were taken at 4 months after inoculation. 
were not chlorotic in the greenhouse. For example, Eureka lemon and sour orange, which in the greenhouse conditions had no or very minimal symptoms, showed pronounced chlorotic symptoms on leaves under continuous light by 4 months after inoculation. Some cultivars with variable symptoms (i.e., Siamese Sweet and Ling Ping Yau pummelos and $C$. indica) that developed mild symptoms in the greenhouse developed strong chlorosis when incubated under the continuous light conditions.

Changing of light conditions by switching infected symptomatic trees from the greenhouse to the continuous light growth room and those that were incubated in the growth room to the greenhouse at 7 months after the beginning of the experiment did not significantly affect existing symptoms in most cultivars. In general, the highly chlorotic leaves of the light-room-incubated trees changed little when shifted to the greenhouse but new flushes of new leaves exhibited normal greenhouse-type symptoms. With one exception, the relatively mild chlorotic leaves and asymptomatic leaves of the greenhouse trees did not quickly increase in chlorosis when shifted to the 24-h-light growth room. The exception was $C$. indica, whose asymptomatic and lightly chlorotic leaves quickly became extremely chlorotic within 2 weeks after the shift to continuous light (Fig. 4). Incubation of ' $\mathrm{Ca}$. L. asiaticus'-infected Sun Chu Sha mandarin plants at three different temperatures- $20^{\circ} \mathrm{C}, 27^{\circ} \mathrm{C}$, or $32^{\circ} \mathrm{C}$-resulted in approximately the same ' $\mathrm{Ca}$. L. asiaticus' titers and symptom induction at each of these temperatures in these plants (data not shown).

'Ca. L. asiaticus'-CTV interaction. Co-infection of HLB with one of the five CTV strains (T36, T30, T68, T3, or VT) on the three citrus cultivars tested did not reveal any synergistic effect of the presence of the two pathogens, which could be noted as a change in severity of symptoms or increase or decrease in levels of accumulations of one or both pathogens (Table 2). Plants infected with ' $\mathrm{Ca}$. L. asiaticus' along with one of the CTV strains listed above displayed characteristic HLB symptoms, with the severity of symptoms depending on the degree of susceptibility of the particular cultivar to ' $\mathrm{Ca}$. L. asiaticus' plus typical CTV symptoms, which usually vary among strains of the virus. Levels of accumulation of either ' $\mathrm{Ca}$. L. asiaticus' or CTV were not affected by the presence of the second pathogen (Table 2).

\section{DISCUSSION}

Isolates of ' $\mathrm{Ca}$. L. asiaticus' collected from different parts of the world have different pathogenicity phenotypes (23). Since Florida is one of the premier citrus production region in the United States, it is very important to characterize pathogenicity and virulence of ' $\mathrm{Ca}$. L. asiaticus' isolates collected in this area as well. Because it is impossible to predict which ' $\mathrm{Ca}$. L. asiaticus'
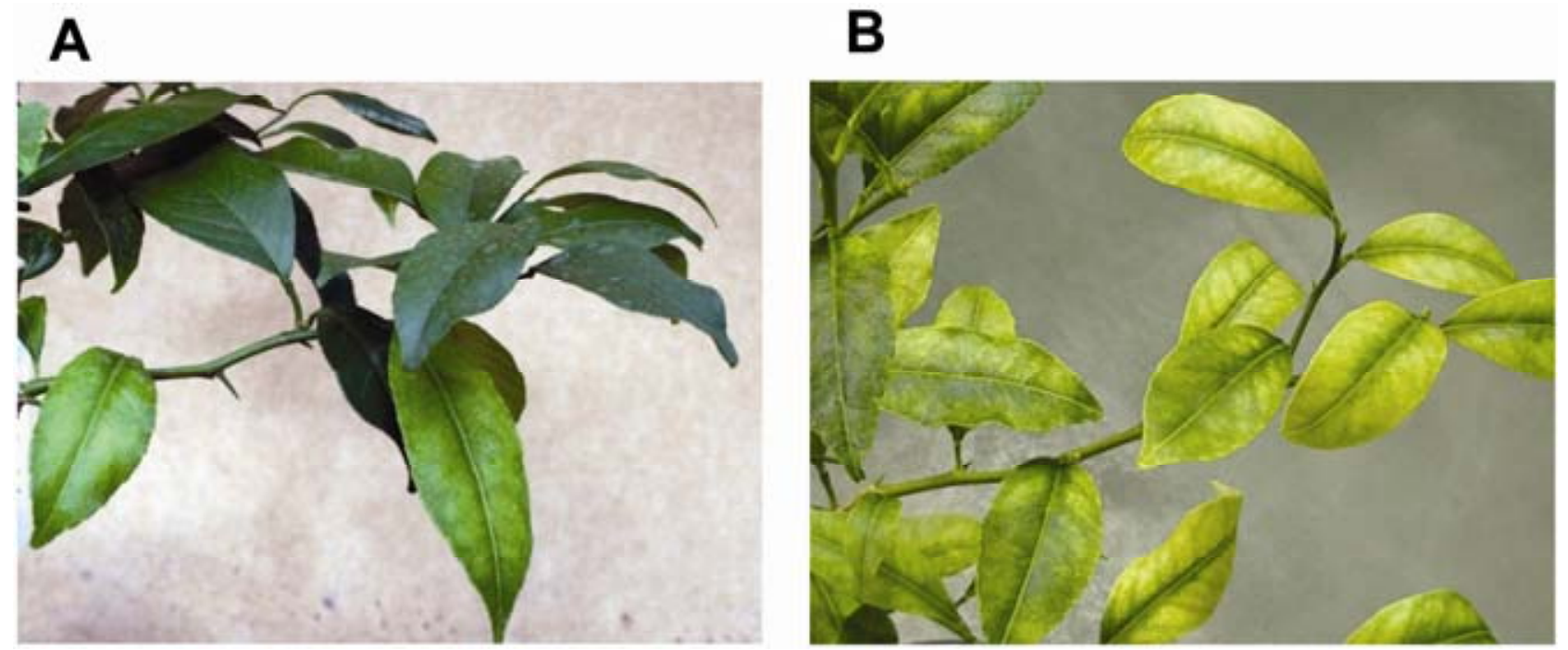

Fig. 4. Effect of change of light conditions on symptoms development in 'Candidatus Liberibacter asiaticus'-infected Citrus indica. A, 'Ca. L. asiaticus'-infected plant kept in the greenhouse 7 months after graft inoculation; B, the same plant 2 weeks after the shift to the growth room with a 24-h photoperiod.

TABLE 2. Analysis of 'Candidatus Liberibacter asiaticus' and Citrus tristeza virus (CTV) accumulation in citrus trees inoculated with both pathogens

\begin{tabular}{|c|c|c|c|c|c|c|}
\hline \multirow[b]{2}{*}{ Experimental group } & \multicolumn{2}{|c|}{ Citrus macrophylla } & \multicolumn{2}{|c|}{ Valencia sweet orange } & \multicolumn{2}{|c|}{ Volkamer lemon } \\
\hline & Ct value ${ }^{\mathrm{a}}$ & CTV titer $^{\mathrm{b}}$ & $\mathrm{Ct}$ value & CTV titer & $\mathrm{Ct}$ value & CTV titer \\
\hline Healthy & Undetected & $0.05 \pm 0.008$ & Undetected & $0.04 \pm 0.006$ & Undetected & $0.04 \pm 0.007$ \\
\hline FC6 & $26.6 \pm 0.45$ & $0.04 \pm 0.007$ & $25.8 \pm 0.39$ & $0.04 \pm 0.009$ & $22.5 \pm 0.25$ & $0.05 \pm 0.006$ \\
\hline $\mathrm{FC} 6+\mathrm{T} 36$ & $26.6 \pm 0.12$ & $3.26 \pm 0.065$ & $25.9 \pm 0.19$ & $1.63 \pm 0.014$ & $22.2 \pm 0.20$ & $2.10 \pm 0.016$ \\
\hline $\mathrm{FC6}+\mathrm{T} 30$ & $27.0 \pm 0.23$ & $2.11 \pm 0.015$ & $25.7 \pm 0.18$ & $2.26 \pm 0.020$ & $22.9 \pm 0.35$ & $1.77 \pm 0.015$ \\
\hline $\mathrm{FC6}+\mathrm{T} 68$ & $27.1 \pm 0.10$ & $3.32 \pm 0.021$ & $24.0 \pm 0.51$ & $3.12 \pm 0.019$ & $23.0 \pm 0.42$ & $3.10 \pm 0.065$ \\
\hline $\mathrm{FC} 6+\mathrm{T} 3$ & $27.4 \pm 0.26$ & $3.34 \pm 0.032$ & $24.7 \pm 0.32$ & $3.25 \pm 0.022$ & $23.1 \pm 0.29$ & $2.79 \pm 0.043$ \\
\hline $\mathrm{FC} 6+\mathrm{VT}$ & $28.0 \pm 0.30$ & $3.17 \pm 0.030$ & $26.9 \pm 0.36$ & $2.87 \pm 0.015$ & $29.7 \pm 0.56$ & $1.86 \pm 0.015$ \\
\hline $\mathrm{T} 36$ & Undetected & $3.33 \pm 0.027$ & Undetected & $1.82 \pm 0.010$ & Undetected & $2.56 \pm 0.019$ \\
\hline $\mathrm{T} 30$ & Undetected & $3.10 \pm 0.018$ & Undetected & $3.13 \pm 0.022$ & Undetected & $1.67 \pm 0.012$ \\
\hline T68 & Undetected & $3.35 \pm 0.025$ & Undetected & $3.38 \pm 0.030$ & Undetected & $2.45 \pm 0.026$ \\
\hline $\mathrm{T} 3$ & Undetected & $3.35 \pm 0.016$ & Undetected & $1.85 \pm 0.012$ & Undetected & $1.46 \pm 0.021$ \\
\hline VT & Undetected & $2.93 \pm 0.019$ & Undetected & $2.45 \pm 0.019$ & Undetected & $1.06 \pm 0.010$ \\
\hline
\end{tabular}

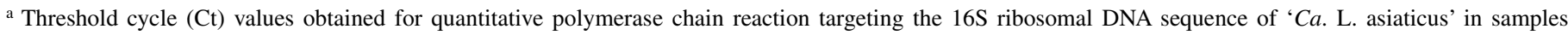
collected from infected trees at 7 months after inoculation.

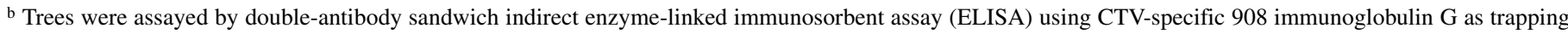
antibody at a concentration of $1 \mu \mathrm{g} / \mathrm{ml}$ and ECTV 172 monoclonal antibody as detecting antibody at a 1:50,000 dilution. Ct and ELISA values (absorbance at 405 $\mathrm{nm})$ are averages for three plants \pm standard deviation. 
hosts would reveal differential reactions, it is important to examine several isolates against a range of different citrus cultivars and relatives. However, because ' $C a$. L. asiaticus' was a Select Agent, we had limited greenhouse space for extensive experiments. Therefore, we chose three representative isolates collected from three citrus-growing areas in Florida for this study. One problem with collecting sources of HLB in Florida is that most HLB infections occur in trees with preexisting CTV infections, so that most HLB-infected samples also contain CTV. CTV can be removed from the inoculum by passaging ' $\mathrm{Ca}$. L. asiaticus' through a CTV-resistant host but this requires at least 6 months. In this study, one isolate did not contain CTV and two isolates did. However, all three inoculum sources demonstrated similar virulence and caused similar symptom phenotypes in the six citrus hosts, which suggested that the HLB isolates were similar and could have resulted from a common introduction.

Although the same citrus hosts responded similarly to inoculation with each of three HLB inocula, there was substantial variation among different citrus genotypes in their reactions to infection. Based on the symptoms developed and the ability of plants to continue growth, the citrus genotypes were grouped into four categories: sensitive, which exhibited severe chlorosis on leaves, usually on young terminal portions of branches, greatly reduced growth, and eventual death; moderately tolerant, with some scattered distinct symptoms but little or no growth reduction and no plant death; tolerant, with very minimal symptoms; and genotypes with variable reactions in which some shoots showed acute symptoms and lack of terminal growth but other branches showed reduced leaf symptoms and continued growth. Remarkably, we observed similar bacterial titers in most citrus cultivars, which showed substantial differences in their reactions to ' $\mathrm{Ca}$. L. asiaticus', demonstrating that there was no strict parallel between bacterial titer and host response.

Field observations demonstrate that, usually, symptoms are unevenly distributed within infected trees, which represents one of the major difficulties for detection of the disease $(2,4,17,18)$. In our experiments, the distribution of symptoms in some of the citrus genotypes was also sporadic. To assess whether fluctuation of the bacterial concentration correlated with the uneven symptom development, we examined ' $C a$. L. asiaticus' distribution within individual plants of several citrus genotypes, with particular interest in moderately tolerant cultivars with intermittent patterns of symptoms and with sharp transitions from symptomatic leaves to adjacent nonsymptomatic leaves. In all citrus hosts, ' $\mathrm{Ca}$. L. asiaticus' was unevenly distributed, with higher titers of the bacterium found within symptomatic tissue. However, even nonsymptomatic areas occasionally tested positive for the bacterium. This pattern of infection makes it difficult to predict where ' $\mathrm{Ca}$. L. asiaticus' is located if symptoms are absent. The uneven distribution of ' $\mathrm{Ca}$. L. asiaticus' in infected trees reduces the ability to efficiently transmit HLB by grafting. Nevertheless, efficiencies of pathogen graft transmission in our experiments averaged $\approx 70$ to $90 \%$ for all citrus cultivars. This observation differs from the published results for ' $\mathrm{Ca}$. L. americanus' (14). In their experiments, there was significant variation in pathogen transmission among different citrus cultivars. Furthermore, although highly symptomatic tissue was usually used as an inoculum source for experimental inoculation of plants with HLB, we demonstrated that there often was enough inoculum present in asymptomatic tissue to infect susceptible plants. Nevertheless, taking into consideration the uneven distribution of ' $\mathrm{Ca}$. L. asiaticus' in infected trees and, in some cases, the low transmission rate of this pathogen, we would not recommend using asymptomatic tissues for inoculum.

Earlier work and more recent observations have shown that there is a correlation between disruption of the sugar movement pathway and the appearance of chlorotic symptoms in leaves of HLB-infected trees $(1,10,18,20)$. The lack of sugar export leads to accumulation of starch granules within chloroplasts, often to the point of chloroplast disruption, which results in chlorotic leaves. Sometimes, the chlorosis occurs within small sectors of leaves, resulting in an uneven blotchy mottle symptom. At other times, all upstream leaves become uniformly chlorotic, suggesting that phloem blockage occurs in the stem below. Because of the correlation between starch accumulation and disease symptoms, we examined HLB symptom production under conditions of increased photosynthesis. Overall, the continuous light conditions increased symptom expression in infected plants, particularly in more tolerant genotypes, and reduced the time before distinctive symptoms developed, which is an aid to routine biological assays. Because the amount of sugar production due to the extended periods of photosynthesis would be expected to increase, the increase in severity of HLB symptoms under these conditions provides additional evidence of the correlation of disease symptoms and disruption of phloem translocation of carbohydrates coupled with abnormal accumulation of starch in leaves of infected trees.

It has been reported that CTV-infected trees in South Africa might have some protection against citrus greening (24). CTV is widespread throughout commercial citrus in Florida, with two strains being predominant: T30, which does not cause any noticeable disease, and T36, which causes decline and death of trees propagated on the sour orange rootstock. In addition, members of the VT strain were recently found in Florida (19). Because of the wide distribution of CTV in commercial citrus, most fieldcollected isolates of ' $\mathrm{Ca}$. L. asiaticus' are co-infected with CTV. Also, because both pathogens are localized to phloem cells, we investigated possible interactions of these diseases. However, examination of the ' $\mathrm{Ca}$. L. asiaticus'-CTV interaction in the initial experiment with ' $\mathrm{Ca}$. L. asiaticus' isolates containing uncharacterized populations of CTV and, further, in the experiment in which ' $\mathrm{Ca}$. L. asiaticus' was co-inoculated into plants along with known Florida CTV strains did not reveal any synergistic effect of the presence of the two pathogens, indicating that these pathogens likely co-exist in the same citrus plants without interaction.

One of the more important questions of citrus HLB research is: what makes some citrus cultivars highly tolerant to HLB and others extremely sensitive to the extent of death from the disease? Clearly, ' $\mathrm{Ca}$. L. asiaticus' does not cause severe disease in all of the trees in which it multiplies to high titers. Additionally, in some cases (Carrizo citrange, for example), the bacterium does not multiply appreciably or cause an obvious host response but survives in the plant and can be graft transmitted to another host. However, within an individual plant, higher titers of the bacterium are usually associated with symptomatic areas if symptoms are produced. Answering this question is crucial for the understanding of mechanisms of pathogenicity of the HLB bacterium and in order to develop effective disease management strategies. We trust that observations reported here will provide reagents for further examination of the ' $\mathrm{Ca}$. L. asiaticus'-citrus interaction to advance the understanding of how ' $\mathrm{Ca}$. L. asiaticus' causes disease and to develop diagnostic methods or resistant cultivars to better manage this disease.

\section{ACKNOWLEDGMENTS}

This research was supported by the Florida Agricultural Experiment Station, grants from the Florida Citrus Production Research Advisory Council (FCPRAC) and an endowment from the J. R. and Addie Graves family. We thank T. Shilts, C. Graffam, and R. McCoy for excellent technical assistance.

\section{LITERATURE CITED}

1. Achor, D. S., Chung, K.-R., Exteberria, E., Wang, N., and Albrigo, L. G. 2008. Anatomical evolution of symptoms from infection with the HLB bacterium. Proc. Int. Res. Conf. Huanglongbing No. 5.3. Orlando, FL.

2. Bové, J. M. 2006. Huanglongbing: A destructive, newly-emerging, century-old disease of citrus. J. Plant Pathol. 88:7-37. 
3. Chen, J., Pu, X., Deng, X., Liu, S., Li, H., and Civerolo, E. 2009. A phytoplasma related to 'Candidatus Phytoplasma asteri' detected in citrus showing huanglongbing (yellow shoot disease) symptoms in Guangdong, P.R. China. Phytopathology 99:236-242.

4. da Graça, J. V. 1991. Citrus greening disease. Annu. Rev. Phytopathol. 29:109-36.

5. da Graça, J. V., and Korsten, L. 2004. Citrus huanglongbing: Review, present status and future strategies. Pages 229-245 in: Diseases of Fruits and Vegetables, Volume I. S. A. M. H. Naqvi, ed. Kluwer Academic Press, Dordrecht, The Netherlands.

6. Fraser, L. R., and Singh, D. 1969. Reaction of Indian citrus varieties to greening virus. Pages 365-366 in: Proc. First Int. Citrus Symp. H. D. Chapman, ed. Publications Department of the University of California, Riverside.

7. Garnsey, S. M., and Cambra, M. 1991. Enzyme-linked immunosorbent assay (ELISA) for citrus pathogens. Pages 193-216 in: GraftTransmissible Diseases of Citrus. Handbook for Detection and Diagnosis. C. N. Roistacher, ed. FAO, Rome.

8. Gonzales, C. I., Vinas, R. C., and Vergara, L. A. 1972. Observations of 110 citrus cultivars in an area severely infested by leaf mottling. Pages 3840 in: Proc. Fifth Conf. Int. Organ. Citrus Virol. Tokyo. W. C. Price, ed. University of Florida Press, Gainesville.

9. Gottwald, T. R. 2007. Citrus canker and citrus huanglongbing, two exotic bacterial diseases threatening the citrus industries of the western hemisphere. Outlooks Pest Manage. 18(6):274-279.

10. Kim, J. S., Sagaram, U. S., Burns, J. K., Li, J. L., and Wang, N. 2009. Response of sweet orange (Citrus sinensis) to 'Candidatus Liberibacter asiaticus' infection: Microscopy and microarray analyses. Phytopathology 99:50-57.

11. Koizumi, M., Prommintara, M., Linwattana, G., and Kaisuwan, T. 1993. Field evaluation of citrus cultivars for greening disease resistance in Thailand. Pages 274-279 in: Proc. Twelfth Conf. Int. Organ. Citrus Virol. New Delhi, India. P. Moreno, J. V. da Graça, and L. W. Timmer, eds. International Organization of Citrus Virologists, University of California, Riverside.

12. Li, W., Hartung, J. S., and Levy, L. E. 2006. Quantitative real time PCR for detection and identification of 'Candidatus Liberibacter species' associated with citrus huanglongbing. J. Microbiol. Methods 66:104-115.

13. Li, W., Levy, L., and Hartung, J. S. 2009. Quantitative distribution of 'Candidatus Liberibacter asiaticus' in citrus plants with citrus huanglongbing. Phytopathology 99:139-144.

14. Lopes, S. A., and Frare, G. F. 2008. Graft transmission and cultivar reaction of citrus to 'Candidatus Liberibacter americanus.' Plant Dis. 92:21-24.

15. Lopes, S. A., Frare, G. F., Bertolini, E., Cambra, M., Fernandes, N. G., Ayres, A. J., Marin, D. R., and Bové, J. M. 2009. Liberibacters associated with citrus huanglongbing in Brazil: 'Candidatus Liberibacter asiaticus' is heat tolerant, 'Ca. L. americanus' is heat sensitive. Plant Dis. 93:257-262.

16. Manjunath, K. L., Halbert, S. E., Ramadugu, C., Webb, S., and Lee, R. F. 2008. Detection of 'Candidatus Liberibacter asiaticus' in Diaphorina citri and its importance in the management of citrus huanglongbing in Florida. Phytopathology 98:387-396.

17. Martinez, A. L., Nora, D. M., and Price, W. C. 1971. Observations on greening in the Philippines. Anim. Husb. Agric. J. 6(3):21-22.

18. Schneider, H. 1968. Anatomy of greening-diseased sweet orange shoots. Phytopathology 58:1155-1160.

19. Sieburth, P. J., Nolan, K. G., Hilf, M. E., Lee, R. F. Moreno, P., and Garnsey, S. M. 2005. Discrimination of stem-pitting from other isolates of Citrus tristeza virus. Pages 1-10 in: Proc. Sixteenth Conf. Int. Organ. Citrus Virol. Monterrey, Mexico. M. E. Hilf, N. Duran-Vila, and M. A. Rocha-Pena, eds. International Organization of Citrus Virologists, University of California, Riverside.

20. Takushi, T., Toyozato, T., Kawano, S., Taba, S., Taba, K., Ooshiro, A., Numazawa, M., and Tokeshi, M. 2007. Scratch method for simple, rapid diagnosis of citrus huanglongbing using iodine to detect high accumulation of starch in the citrus leaves. Jpn. J. Phytopathol. 71:3-8.

21. Tatineni, S., Sagaram, U. S., Gowda, S., Robertson, C., Dawson, W. O., Iwanami, T., and Wang, N. 2008. In planta distribution of 'Candidatus Liberibacter asiaticus' as revealed by polymerase chain reaction (PCR) and real-time PCR. Phytopathology 98:592-599.

22. Teixeira, D. C., Wulff, N. A., Martins, E. C., Kitajima, E. W., Bassanezi, R., Ayres, A. J., Eveillard, S., Saillard, C., and Bové, J. M. 2008. A phytoplasma closely related to the pigeon pea witches'-broom phytoplasma (16Sr IX) is associated with citrus huanglongbing symptoms in the state of Sao Paulo, Brazil. Phytopathology 98:977-984.

23. Tsai, C. H., Hung, T. H., and Su, J. H. 2008. Strain identification and distribution of citrus huanglongbing bacteria in Taiwan. Bot. Stud. 49:4956.

24. van Vuuren, S. P., van der Vyver, J. B., Luttig, M., and da Graça, J. V. 2000. Low incidence of huanglongbing fruit symptoms in Valencia sweet orange in the presence of a population of tristeza virus. Pages 373-377 in: Proc. Fourteenth Conf. Int. Organ. Citrus Virol. Campinas, Sao Paulo, Brazil. J. V. da Graça, R. F. Lee, and R. K. Yokomi, eds. International Organization of Citrus Virologists, University of California, Riverside. 